\title{
Evaluation of Potential Risk Factors Causing Abdominal Wound Dehiscence
}

\author{
Ajay Kumar Jha ${ }^{\oplus 1}$, Santosh Kumar ${ }^{\circledR 2}$, Ajit Kumar Sinha ${ }^{2}$ \\ ${ }^{1}$ Associate Professor, Department of Surgery, Anugrah Narayan Magadh Medical College and Hospital, Gaya, Bihar, India, ${ }^{2}$ Assistant Professor, Department of Surgery, \\ Anugrah Narayan Magadh Medical College and Hospital, Gaya, Bihar, India.
}

\section{Abstract}

Background: Wound dehiscence/burst abdomen is a very serious post-operative complication associated with high morbidity and mortality. The aim of this study was to highlight the risk factors for wound dehiscence and remedial measures to prevent or reduce the incidence of wound dehiscence. Subjects and Methods: This is a prospective and observational study involving all those who have developed abdomen wound dehiscence after initial surgery, an elaborative study of these cases with regard to date of admission, clinical history regarding the mode of presentation, significant risk factors, investigations, time of surgery and type of surgery postoperatively, study of diagnosis and day of diagnosis of wound dehiscence is done till the patient is discharged from the hospital. The collected data is analysed and statistics were made according to need. Results: The incidence of abdominal wound dehiscence is more common in male patients in 4th to 5th decade. Patients with peritonitis due to duodenal perforation, complicated appendicitis, pyoperitoneum and intestinal obstruction carried higher risk of abdominal wound dehiscence. Abdominal wound dehiscence was more common in patients operated in emergency. Patients with intra-abdominal infection, anaemia, hypoalbuminaemia, jaundice had higher incidence of wound dehiscence. Conclusion: Wound dehiscence can be prevented by improving nutritional status of patient, proper surgical technique, controlling infections and correcting co-morbid conditions.

Keywords: Abdominal wound dehiscence, Laparotomy, Malnutrition, Peritonitis, Pyoperitoneum

Corresponding Author: Santosh Kumar, Assistant Professor, Department of Surgery, Anugrah Narayan Magadh Medical College and Hospital, Gaya, Bihar, India.

E-mail: santoshmch04@gmail.com

Received: 17 December 2019

Revised: 24 January 2020

Accepted: 29 January 2020

Published: 26 May 2020

\section{Introduction}

Abdominal wound dehiscence (burst abdomen, fascial dehiscence) is a severe postoperative complication with mortality rates reported as high as $45 \% .{ }^{[1-3]}$ Abdominal wound dehiscence can result in evisceration, which require immediate treatment. Prolonged hospital stays, high incidence of incisional hernia and subsequent reoperations underline the severity of this complication.

Wound dehiscence is described as partial or complete disruption of an abdominal wound closure with or without protrusion and evisceration of abdominal contents. Conditions associated with increased risk of wound dehiscence are anaemia, hypoalbuminaemia, malnutrition, malignancy, jaundice, obesity and diabetes, male gender, elderly patients and specific surgical procedures as colon surgery or emergency laparotomy. ${ }^{[4]}$ Despite advances in perioperative care and suture materials, incidence and mortality rates with regards to abdominal wound dehiscence have not significantly changed over the past decades.

This may be attributable to increasing incidences of risk factors within patient populations outweighing the benefits of technical achievements. Several mainly retrospective studies have been performed to identify risk factors for this complication often presenting conflicting results. The goal of the underlying study was to evaluate possible risk factors for abdominal wound dehiscence. This can be used to assess the risk for individual patients and it may prove useful for prevention strategies in clinical studies.

\section{Subjects and Methods}

The study was conducted at ANMMCH, Gaya. The study was approved by the institutional research committee. This is a prospective and observational study involving all those who have developed abdomen wound dehiscence after initial surgery.

\section{Inclusion criteria}


- Patients of age $>20$ years and of either sex who have developed abdominal wound dehiscence following either emergency or elective abdominal surgeries who are willing for investigations and treatment.

- All patients were examined for their presentation, course of disease, various examination and investigations. These records were also analyzed for surgical interventions and outcome.

\section{Exclusion criteria}

- All patients with wound dehiscence who are less than 20 years of age

- Patients with incisional Hernia

- Patients with wound dehiscence on sites other than the abdomen

- Female patients who developed wound dehiscence after any gynecological procedures

- Patients who have developed wound dehiscence after second surgery.

An elaborative study of these cases with regard to date of admission, clinical history regarding the mode of presentation, significant risk factors, investigations, time of surgery and type of surgery and postoperatively, study of diagnosis and day of diagnosis of wound dehiscence is done till the patient is discharged from the hospital. In history, details regarding presenting complaints, duration, associated diseases, significant risk factors like, anaemia, malnutrition, chronic cough, were noted. Details regarding the clinical diagnosis, whether the operation was conducted in emergency or electively, was noted. Intraoperative findings were noted. The type of surgical procedure done was recorded. Postoperatively the wound dehiscence was diagnosed according to the definitions given in oxford text book of surgery 2 nd edition. The collected data is analysed and statistics were made using SPSS Software version 13.0.

\section{Results}

Total of 930 patients underwent open abdominal surgery between January 2018 to June 2019.

\section{Gender distribution}

Out of 50 cases, 35 were male $(70 \%)$ and 15 were female $(30 \%)$ [Figure 1].

\section{Incidence}

Incidence of wound dehiscence amongst them was $5.38 \%$ (50/930). [Table 1]

Table 1: Incidence of wound dehiscence.

\begin{tabular}{lll}
\hline Total cases & Incidence & Percentage $(\%)$ \\
930 & 50 & 5.38 \\
\hline
\end{tabular}

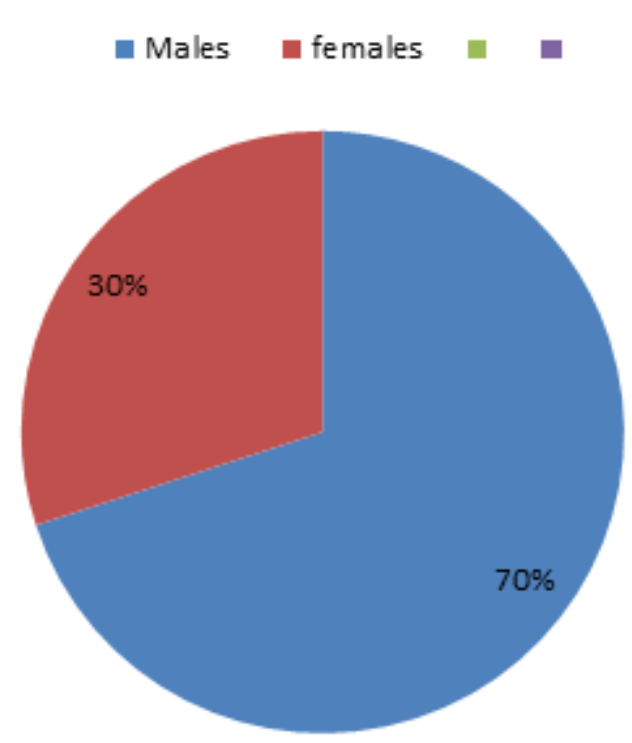

Figure 1: Gender wise distribution

\section{Age distribution}

Abdominal wound dehiscence was seen at all ages, the most common age group was found to be $41-50$ years $(28 \%)$ followed by $31-40$ years $(24 \%)$ [Table 2].

Table 2: Incidence of abdominal wound dehiscence in different age groups.

\begin{tabular}{lll}
\hline Age (years) & No. of patients & Percentage (\%) \\
\hline $20-30$ & 5 & 10 \\
$31-40$ & 12 & 24 \\
$41-50$ & 14 & 28 \\
\hline $51-60$ & 10 & 20 \\
$61-70$ & 6 & 12 \\
$71-80$ & 3 & 6 \\
\hline Total & 50 & 100 \\
\hline
\end{tabular}

\section{Underlying Intra-abdominal Pathology}

Out of 50 cases of wound dehiscence, 30(60\%) patients had peritonitis due to hollow viscus perforation secondary to duodenal ulcer, gastric or small bowel perforation, $6(12 \%)$ patients had complicated appendicitis, 5(10\%) patients had pyoperitonium, 4(8\%) patients were diagnosed with intestinal obstruction which included cases like gangrenous bowel, strictures and adhesions. 2(4\%) cases were malignancy which included carcinoma stomach and colon. Blunt injury, stab injury formed the underlying pathology in few cases [Table 3]. 
Table 3: Distribution of patients with abdominal wound dehiscence according to underlying intraabdominal pathology.

\begin{tabular}{lll}
\hline Diagnosis & $\begin{array}{l}\text { No. } \\
\text { of } \\
\text { patien }\end{array}$ & Percentage (\%) \\
$\begin{array}{l}\text { Gastrointestinal per- } \\
\text { foration }\end{array}$ & 30 & 60 \\
$\begin{array}{l}\text { Complicated appen- } \\
\text { dicitis }\end{array}$ & 6 & 12 \\
\hline $\begin{array}{l}\text { Pyoperitoneum } \\
\text { Intestine obstruction }\end{array}$ & 5 & 10 \\
\hline $\begin{array}{l}\text { Penetrating abdomi- } \\
\text { nal injury }\end{array}$ & 2 & 4 \\
$\begin{array}{l}\text { Blunt abdominal } \\
\text { trauma }\end{array}$ & 1 & 2 \\
\hline $\begin{array}{l}\text { Carcinoma asc. } \\
\text { Colon }\end{array}$ & 1 & 2 \\
\hline $\begin{array}{l}\text { Carcinoma rectosig- } \\
\text { moid junction }\end{array}$ & 1 & 2 \\
\hline
\end{tabular}

\section{Timing of surgery}

Wound dehiscence in our study was found to be more common in emergency surgeries $46(92 \%)$ compared to elective surgeries $4(8 \%)$ [Table 4 ].

Table 4: Timing of surgery.

\begin{tabular}{lll}
\hline Type of surgery & No. of patients & Percentage (\%) \\
\hline Emergency & 46 & 92 \\
Elective & 4 & 8 \\
Total & 50 & 100 \\
\hline
\end{tabular}

\section{Preoperative causes}

In present study 44 out of 50 patients had intra-abdominal infection making it the most common and important preoperative risk factor (88\%). Hypoalbuminaemia was found in $30(60 \%)$ patients. Anaemia was present in $28(56 \%)$ patients. Diabetes (30\%), uremia (28\%) and jaundice (16\%) were other significant preoperative risk factors in that order. Most patients had more than one risk factors present [Table 5].

\section{Post-operative Causes}

Wound contamination remained the most common postoperative cause of wound dehiscence. 45 out of 50 patients had wound contamination (90\%). Cough was present in 22 patients (44\%). Abdominal distension (36\%) and vomiting (28\%) were the other common post- operative causes [Table 6].

\section{Anaemia}

\begin{tabular}{|c|c|c|}
\hline $\begin{array}{l}\text { Preoperative } \\
\text { causes }\end{array}$ & No. of patients & Percentage (\%) \\
\hline $\begin{array}{l}\text { Intra-abdominal } \\
\text { infection }\end{array}$ & 44 & 88 \\
\hline Hypoalbuminaemi & 30 & 60 \\
\hline Anaemia & 28 & 56 \\
\hline Diabetes & 15 & 30 \\
\hline Uremia & 14 & 28 \\
\hline Jaundice & 8 & 16 \\
\hline Malignancy & 1 & 2 \\
\hline
\end{tabular}

Table 6: Postoperative causes.

\begin{tabular}{lll}
\hline $\begin{array}{l}\text { Postoperative } \\
\text { causes }\end{array}$ & No. of patients & Percentage (\%) \\
$\begin{array}{l}\text { Wound con- } \\
\text { tamination }\end{array}$ & 45 & 90 \\
$\begin{array}{l}\text { Cough } \\
\text { Abdominal dis- } \\
\text { tension }\end{array}$ & 18 & 44 \\
\hline Vomiting & 14 & 36 \\
\hline
\end{tabular}

Out of 50 cases of wound dehiscence, 28 patients were having $\mathrm{Hb} \%<10$ gm $\%$. Further, 22 patients were having more than $10 \mathrm{gm} \%$ [Table 7].

Table 7: Hemoglobin.

\begin{tabular}{lll}
\hline Hb $(\mathbf{g m} \%)$ & No. of patients & Percentage $(\%)$ \\
$>10 \mathrm{gm} \%$ & 22 & 44 \\
$<10 \mathrm{gm} \%$ & 28 & 56 \\
Total & 50 & 100 \\
\hline
\end{tabular}

\section{Liver function tests}

Out of 50 cases 8 patients had serum bilirubin $>1.2 \mathrm{mg} / \mathrm{dl}$ and 30 patients had hypoalbuminaemia (serum albumin $<3.5 \mathrm{mg} / \mathrm{dl}$ ) [Table 8].

\begin{tabular}{|c|c|c|c|}
\hline \multicolumn{2}{|c|}{ Liver function test } & \multirow{2}{*}{$\begin{array}{l}\text { No. of } \\
\text { patients } \\
8\end{array}$} & \multirow{2}{*}{$\begin{array}{l}\text { Percentage }(\%) \\
16\end{array}$} \\
\hline Serum & $>1.2$ & & \\
\hline $\begin{array}{l}\text { Bilirubin } \\
\text { (mg/dl) }\end{array}$ & $\begin{array}{l}0.4- \\
1.1\end{array}$ & 42 & 84 \\
\hline Serum & $<3.5$ & 30 & 60 \\
\hline $\begin{array}{l}\text { Albumin } \\
(\mathrm{mg} / \mathrm{dl})\end{array}$ & $\begin{array}{l}3.5- \\
5.5\end{array}$ & 20 & 40 \\
\hline
\end{tabular}




\section{Discussion}

Acute wound failure is also known as wound dehiscence, burst abdomen, wound disruption and evisceration. It is a very serious complication of abdominal surgery, which carries very high mortality rate. It is a multi-factorial problem. Western studies showed an incidence of 0.4 to $3.5 \%$.

In present study, incidence of wound dehiscence was 5.38\%. The higher frequency of burst abdomen is, in contrast with many Western studies which showed an incidence of 0.4 to $3.5 \%$ but is in accordance with the study done by Mathur et al which showed that the problem of wound dehiscence is much more prevalent in South East Asia than the Western world. ${ }^{[5]}$ This may be attributable to poor nutritional state of the patients, delayed presentation to the tertiary care hospitals, poor quality of suture material, diseases like tuberculosis of the abdomen which is endemic in the countries of South East Asia and higher load of emergency surgeries.

In present study, out of 50 patients who had wound dehiscence, 35 were males and females were 15 in number with the ratio of 2.33:1. The male predominance was due to the higher incidence of peptic ulcer perforation, intestinal obstruction and malignancies in male sex.

In present study, wound dehiscence was commonest in the age group of 41-50 years. The mean age of presentation was 48.8 years. In present study wound dehiscence was found in younger age group as incidence of perforation and intestinal obstruction was common in this age group. Spiliotis et al, showed the incidence of abdominal wound dehiscence more commonly in male gender $(60 \%)$ and with the mean age of 69.5 years. ${ }^{[6]}$ Most of the patients who underwent laparotomy had malignancy and diverticular disease. 15 out of 3500 patients developed wound dehiscence $(0.43 \%)$ amongst which $9(60 \%)$ undergone emergency laparotomy.

In the present study, $92 \%$ of patients of burst abdomen underwent laparotomy in an emergency setup. More chances for wound dehiscence were attributed to poor patient hygiene. The emergency conditions itself have detrimental effect due to the course of acute illness as well as delayed presentation etc. Most of the patients were already having complications like septicaemia and fluid and electrolytes derangements due lack of facilities in nearby local health centres. In emergency laparotomies, surgical wound is not well secured from contaminated contents of the peritoneal cavity. This is one of the factors which can also play a major role in probable explanation for a high prevalence of burst abdomen in our emergency group. Rural hospitals and nursing homes often keep patients with perforation peritonitis on conservative therapy (antibiotics and even steroids). This results in increased intra-abdominal pressure which causes decreased capillary circulation in abdominal wall. This is in accordance to study conducted by Hermosa et al, where wound dehiscence was more common in emergency operation and operations with higher wound classification. ${ }^{[7]}$

In present study, $60 \%$ patients had peritonitis. In patients with peritonitis bowel is oedematous, tissues are friable due to infections and there is increased tension on suture line during abdominal wall closure. Graham DJ et al pointed that intraabdominal infection and colonic surgery were a leading cause of wound dehiscence. ${ }^{[8]}$

Study conducted on 107 patients with abdominal wound dehiscence over a period of 7 years in Department of Surgery, Cleveland Veterans Affairs Medical Centre, Case Western Reserve University USA by Graham et al, showed that patients with Intra-abdominal infection were more likely to have undergone an emergency operations ( $p<0.02)$, wound dehiscence is more common in emergency operations and operations with higher wound classification. ${ }^{[8]}$ Our study showed that abdominal wound dehiscence is more common in patients operated for peritonitis due to hollow viscus perforation and in which wounds were classified as contaminated. $30(60 \%)$ of the patients studied were operated for hollow viscus perforations including duodenal, gastric, ileal and jejunal perforations, $6(12 \%)$ patients had acute appendicitis, 5(10\%) patients had pyoperitonium, $4(8 \%)$ patients were diagnosed with intestinal obstruction which included cases like gangrenous bowel, strictures and adhesions.

In a study carried out by Sivender et al, out of 50 cases $4(8 \%)$ cases had raised liver enzymes, 31(62\%) patients had hypoalbuminaemia, 16 (32\%) patients had hyperbilirubinaemia and $18(36 \%)$ patients had elevated renal parameters. ${ }^{[9]}$ In present study out of 50 patients about $88 \%$ of patients showed intra-abdominal infection. Other risk factors in present study included, Hypoalbuminaemia $60 \%$, anaemia $56 \%$, diabetes mellitus $30 \%$, uremia $28 \%$ and jaundice $16 \%$.

In a study carried out by Parmar et al post-operative causes like cough (45\%), abdominal distension due to paralytic ileus $(35 \%)$, vomiting $(10 \%)$ were noted. ${ }^{[10]}$ Wound contamination (73.33\%) remained the most common post-operative cause of wound dehiscence. In present study, 90\% (45) patients had wound contamination. Cough was present in $44 \%$ (22) patients. Abdominal distension 36\% (18) and vomiting $28 \%$ (14) were the other common post-operative causes.

\section{Conclusion}

Abdominal wound dehiscence causes significant morbidity and mortality. Intra-abdominal infection is the most important factor in predicting wound dehiscence. Patient factors like older age group, male sex, anaemia, malnutrition, diabetes, patients with peritonitis due to bowel perforation act as determinant for wound dehiscence. Emergency procedure is prone for burst abdomen. Simple investigations like 
Hemogram, RBS, RFT, LFT, chest x-ray may help to detect predisposing factors. Patients with these risk factors require more attention and special care to minimize the risk of occurrence. Intra-operatively abdominal wound should be secured from the peritoneal contamination, thorough peritoneal lavage should be given, and abdominal wall layers should be closed under aseptic precautions. Postoperatively abdominal wound dehiscence can be prevented by improving the nutritional status of the patient, early mobilization of the patient and chest physiotherapy to avoid respiratory complications and cough.

\section{References}

1. Carlson MA. Acute wound failure. Surg Clin North Am. 1997;77(3):607-643.

2. van Ramshorst GH, Nieuwenhuizen J, Hop WCJ, Arends P, Boom J, Jeekel J, et al. Abdominal Wound Dehiscence in Adults: Development and Validation of a Risk Model. World J Surg. 2010;34(1):20-27. Available from: https://dx.doi.org/10. 1007/s00268-009-0277-y. doi:10.1007/s00268-009-0277-y.

3. Webster C, Neumayer L, Smout R, Horn S, Daley J, Henderson $\mathrm{W}$, et al. Prognostic models of abdominal wound dehiscence after laparotomy. J Surg Res. 2003;109(2):130-137. Available from: https://dx.doi.org/10.1016/s0022-4804(02)00097-5. doi:10.1016/s0022-4804(02)00097-5.

4. Waqar SH, Malik ZI, Razzaq A, Abdullah MT, Shaima A, Zahid MA. Frequency and risk factors for wound dehiscence/burst abdomen in midline laparotomies. J Ayub Med Coll Abbottabad. 2005;17(4):70-73.

5. Mathur SK. Burst abdomen. A preventable complication, monolayer closure of the abdominal incision with monofila- ment nylon. J Postgrad Med. 1983;29(4):223-232.

6. Spiliotis J, Tsiveriotis K, Datsis AD, Vaxevanidou A, Zacharis $\mathrm{G}$, Giafis K, et al. Wound dehiscence: is still a problem in the 21th century: a retrospective study. World J Emerg Surg. 2009;4(1):12-12. Available from: https://dx.doi.org/10.1186/ 1749-7922-4-12. doi:10.1186/1749-7922-4-12.

7. Rodríguez-Hermosa JI, Codina-Cazador A, Ruiz B, Roig J, Gironés J, Pujadas M, et al. Risk factors for acute dehiscence of the abdominal wall after laparotomy in adults. Spanish Surg. 2005;77(5):280-286.

8. Graham DJ, Stevenson JT, Mchenry CR, Lucas C, Smathers $\mathrm{HM}$. The association of intra-abdominal infection and abdominal wound dehiscence/ Discussion. Am Surg. 1998;64(7):660665.

9. Sivender A, Ilaiah M, Reddy GS. A Clinical study on risk factors causing abdominal wound dehiscence and management. IOSR. J Dent Med Sci. 2015;14(10):18-23.

10. Parmar G, Gohil A, Hathila V. Burst abdomen: A grave postoperative complication. Internet J Surg. 2008;20:1-8.

Copyright: (C) the author(s), 2020. It is an open-access article distributed under the terms of the Creative Commons Attribution License (CC BY 4.0), which permits authors to retain ownership of the copyright for their content, and allow anyone to download, reuse, reprint, modify, distribute and/or copy the content as long as the original authors and source are cited.

How to cite this article: Jha AK, Kumar S, Sinha AK. Evaluation of Potential Risk Factors Causing Abdominal Wound Dehiscence. Acad. J Surg. 2020;3(1):21-25.

DOI: dx.doi.org/10.47008/ajs/2020.3.1.5

Source of Support: Nil, Conflict of Interest: None declared. 